\title{
G2 - Avaliação da inovação na organização pública multipropó- sito de saúde: efetividade na atenção clínica com eficiência no uso de recursos
}

Marcelino José Jorge ${ }^{1 \star}$; Maria Inês Fernandes Pimentel ${ }^{1}$; Alexandre Monken Avellar ${ }^{1}$; Cristina Monken Avellar ${ }^{1}$; Daniela de Souza Ferreira ${ }^{1}$; Patrícia Santos Cavalheiro Silva ${ }^{1}$.

\section{1- Fiocruz/INI}

\section{Introdução:}

Para consolidar a inovação nas organizações públicas multipropósito de saúde, a eficiência no uso de recursos complementa a efetividade na atenção clínica. O Instituto Nacional de Infectologia Evandro Chagas da Fundação Oswaldo Cruz (INI), por exemplo, organiza a assistência associada à pesquisa clínica de várias doenças infecciosas segundo o Modelo de Atenção Integral. Hoje, as Ações Integradas (PAI) do Instituto incluem todos os tipos de atividades de pesquisa, ensino, laboratório e atenção clínica do INI. Entre as nosologias focalizadas, a de LTA, incluindo a Leishmaniose Cutânea (LC), ocorre de forma endêmica em várias regiões das Américas. O Brasil e outros seis países do continente concentram cerca de $90 \%$ dos casos de LC. No Brasil, o antimoniato de meglumina (AM) é utilizado como fármaco de primeira linha para o tratamento da LTA e a dose recomendada é de 10-20 mg de antimônio (Sb)/ $\mathrm{kg}$ de peso corporal/dia durante 20 dias, até o máximo de 3 ampolas/dia. Por seu turno, um esquema com dose baixa ( $5 \mathrm{mg} \mathrm{Sb5+/kg} \mathrm{peso} \mathrm{corporal/dia)} \mathrm{durante} 30$ dias seguidos ou intermitentes tem sido eficaz e bem tolerado no tratamento da LTA no Laboratório de Vigilância em Leishmanioses do INI (Lab-Vigileish). A necessidade de se comparar efetividade e segurança entre tais esquemas terapêuticos motivou a realização de um ensaio clínico de fase III para verificação da equivalência entre o esquema padrão e esquemas alternativos de tratamento para LTA com doses baixas de AM no Lab-Vigileish a partir de 2009. Além das conseqüências para a efetividade do tratamento, a experiência acumulada com a adoção desses esquemas alternativos de combinação dos recursos especializados de horas-médicos, material hospitalar, reagentes e medicamentos usados no Lab-Vigileish trouxe indícios de redução das despesas de tratamento da LC. 


\section{Objetivo:}

Avaliar esquemas alternativos no tratamento de LC do ponto de vista da incorporação da dimensão organizacional e da Análise de Eficiência à Análise Custo -Efetividade da inovação na organização pública mutipropósito de saúde.

\section{Metodologia:}

Foi realizada uma avaliação de custoefetividade com os primeiros 59 pacientes com LC desse ensaio, utilizando o modelo Análise Envoltória de Dados (DEA).

\section{Resultados:}

Ao comparar as intervenções para cada paciente com a sua referência (benchmark) na fronteira de eficiência calculada com o modelo DEA, observou-se que havia mais pacientes dos grupos de tratamento com dose baixa de AM do que pacientes dos grupos de dose alta na fronteira eficiente.

\section{Conclusão:}

O grupo de tratamento com dose baixa foi mais eficiente do que o grupo de dose alta. A análise com o modelo DEA destaca os ganhos de desempenho associados à inovação no tratamento de LC no Lab-Vigileish como compatível com uma estratégia pró-eficiência na produção simultânea de serviços de saúde, conhecimento científico e recursos humanos para a pesquisa clínica em doenças infecciosas.

Palavras-Chave: Inovação; Leishmaniose Cutânea; Avaliação tecnológica 